M. Strupp, MD

R. Kalla, MD

J. Claassen, MD

C. Adrion, $\mathrm{MPH}$

U. Mansmann, $\mathrm{PhD}$

T. Klopstock, MD

T. Freilinger, MD

H. Neugebauer, MD

R. Spiegel, $\mathrm{PhD}$

M. Dichgans, MD

F. Lehmann-Horn,

$\mathrm{MD}, \mathrm{PhD}$

K. Jurkat-Rott, MD

T. Brandt, MD, FRCP

J.C. Jen, MD, PhD

K. Jahn, MD

Address correspondence and reprint requests to Dr. Michael

Strupp, Department of

Neurology and IFB ${ }^{\mathrm{LMU}}$,

University of Munich, Campus

Grosshadern, Marchioninistr. 15,

81377 Munich, Germany

michael.strupp@med.uni-muenchen.de

Supplemental data at www.neurology.org

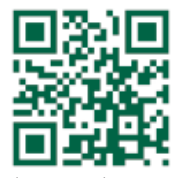

Scan this code with your smartphone to access this feature

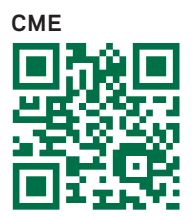

Scan this code with your smartphone to access this feature

\section{A randomized trial of 4-aminopyridine in EA2 and related familial episodic ataxias} 메 $\underline{\underline{\underline{\underline{\underline{u}}}}}$

\section{ABSTRACT}

Objective: The therapeutic effects of 4-aminopyridine (4AP) were investigated in a randomized, double-blind, crossover trial in 10 subjects with familial episodic ataxia with nystagmus.

Methods: After randomization, placebo or 4AP ( $5 \mathrm{mg} 3$ times daily) was administered for 2 3-month-long treatment periods separated by a 1-month-long washout period. The primary outcome measure was the number of ataxia attacks per month; the secondary outcome measures were the attack duration and patient-reported quality of life (Vestibular Disorders Activities of Daily Living Scale [VDADL]). Nonparametric tests and a random-effects model were used for statistical analysis.

Results: The diagnosis of episodic ataxia type 2 (EA2) was genetically confirmed in 7 subjects. Patients receiving placebo had a median monthly attack frequency of 6.50, whereas patients taking 4AP had a frequency of $1.65(p=0.03)$. Median monthly attack duration decreased from 13.65 hours with placebo to 4.45 hours with $4 A P(p=0.08)$. The VDADL score decreased from 6.00 to 1.50 ( $p=0.02)$. 4AP was well-tolerated.

Conclusions: This controlled trial on EA2 and familial episodic ataxia with nystagmus demonstrated that 4AP decreases attack frequency and improves quality of life.

Level of evidence: This crossover study provides Class II evidence that 4AP decreases attack frequency and improves the patient-reported quality of life in patients with episodic ataxia and related familial ataxias. Neurology ${ }^{\circledR} 2011 ; 77: 269-275$

\section{GLOSSARY}

4AP = 4-aminopyridine; EA = episodic ataxia; EA2 = episodic ataxia type 2; IQR = interquartile range; $\mathbf{M S}=$ multiple sclerosis; VDADL = Vestibular Disorders Activities of Daily Living Scale.

Episodic ataxia type 2 (EA2) is a rare autosomal dominant hereditary disorder caused by heterozygous mutations of the gene CACNA1A on chromosome $19 \mathrm{p} 13 .{ }^{1}$ The carbonic anhydrase inhibitor acetazolamide has been the drug of first choice for the preventive treatment of episodic ataxia (EA) and especially EA2 (doses of 250-1,000 mg/day), ${ }^{2,3}$ because of the serendipitous discovery of its dramatic impact. ${ }^{4}$ Its efficacy, however, has never been proven in a randomized controlled trial. ${ }^{5,6}$ Acetazolamide effectively prevents or attenuates the attacks in approximately 50\%-75\% of all patients with EA2.7 Clinical experience, however, shows that many patients stop this treatment in the long run because they develop adverse effects or are no longer responsive. ${ }^{5,6}$ Furthermore, the adverse effects of acetazolamide (such as nephrocalcinosis, hyperhidrosis, paresthesia, muscle stiffening with easy fatigability, and gastrointestinal disturbances) limit its usage. ${ }^{6}$ In view of the need to identify an alternative treatment option to acetazolamide and on the basis of pilot studies in subjects with downbeat nystagmus ${ }^{8}$ and $\mathrm{EA}^{9}$ as well as findings from animal studies, ${ }^{10,11}$ we conducted a prospective randomized, doubleblind, placebo-controlled crossover study of $4 \mathrm{AP}$ in familial EA with nystagmus (the majority

From the Department of Neurology, Friedrich-Baur-Institute and IFB ${ }^{\text {LMU }}$ (M.S., R.K., J.C., T.K., T.F., H.N., R.S., M.D., T.B., K.J.), Institute for Medical Information Sciences, Biometry and Epidemiology (C.A., U.M.), Department of Clinical Neurosciences (T.B.), University of Munich, Germany; Department of Applied Physiology (F.L.-H., K.J.-R.), University of Ulm, Germany; and Department of Neurology (J.C.J.), University of California, Los Angeles.

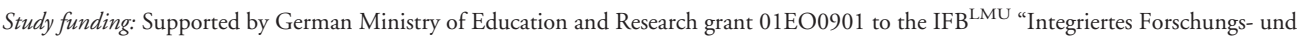
Behandlungszentrum für Schwindel" at the University of Munich, Campus Grosshadern.

Disclosure: Author disclosures are provided at the end of the article. 
of subjects had EA2), in which we assessed its efficacy by determining the frequency and duration of the ataxia attacks as well as patient-reported quality of life as a reflection of disease burden using the Vestibular Disorders Activities of Daily Living (VDADL) scale. ${ }^{12}$ We also evaluated how $4 \mathrm{AP}$ was tolerated by monitoring adverse events throughout the study.

METHODS Standard protocol approvals, registrations, and patient consents. The study was approved by the local ethics committee and was performed in accordance with the Declaration of Helsinki and its subsequent amendments, as well as with the guidelines of Good Clinical Practice. This clinical trial was not registered because patient enrollment began before July 1, 2005. Written informed consent was obtained from subjects who met the study inclusion criteria. All study participants received written information about possible side effects of $4 \mathrm{AP}$ and a standardized protocol with open questions and specific questions about known side effects before they were included in the study. They were instructed to inform the investigator about any side effects of the agent within 24 hours by phone, fax, or e-mail.

Study subject recruitment. Subjects between the ages of 12 and 80 years were recruited from the Neurological Dizziness Unit of the University of Munich and from the genetic database of the Department of Applied Physiology, University of Ulm, Germany (K.J.-R., F.L.-H.). All potential subjects underwent a detailed clinical examination (appendix e-1 on the Neurology ${ }^{\circledR}$ Web site at www.neurology.org). The inclusion criteria were as follows: 1) a history of childhood onset of recurrent attacks of ataxia induced by exercise, stress, or alcohol that last from hours to 1 day; 2) central ocular motor dysfunction such as saccadic smooth pursuit, impaired gaze-holding function, or downbeat nystagmus; and 3) a positive family history or the presence of a disease-causing mutation in the EA2 gene CACNA1A. The exclusion criteria included the following: 1) prolonged QTc time on EKG; 2) structural lesions in the brainstem or cerebellum on T1- or T2-weighted MRI that exceeded a mild atrophy of the cerebellum; 3) inability to comply with the study requirements; 4 ) history of seizures or known epilepsy; 5) pregnancy or childbearing potential without use of approved birth control methods; and 6) known allergy to pyridine-containing substances.

Genetic testing. Genomic DNA was extracted from whole EDTA blood using the salt precipitation method. Mutation screening was performed by PCR amplification and direct sequencing of exons most frequently showing mutations: $4-6,11,13,16,17,22,23,25-27,29-33,35$, and 36 (primers reported in Ophoff et al. ${ }^{1}$ ). PCR products were loaded on a $2 \%$ agarose gel and stained with ethidium bromide; the bands were cut out under ultraviolet light. Bands were then purified using an Amersham Pharmacia kit and cycle-sequenced with 1 pmol of primer using a dye terminator kit (Applied Biosystems). Sequencing was performed on 6\% denaturing polyacrylamide gels in an ABI 377 HT automated sequencer. All sequences with base exchanges were verified by reverse sequencing of a new PCR product of the same DNA sample. A total of 96 control samples were found to be nega- tive for the novel mutations R455X and D1772G, supporting the suspected disease causality.

Study medication dispensing and allocation concealment. The subjects in the study were randomized (by a computer-generated block randomization list) to receive either placebo or 4AP (5 mg 3 times daily). The treatment assignments were performed by providing the appropriate treatment kit to the clinic, which contained the blinded treatments, each in the appropriate order for the patient to whom it was assigned. This assignment was communicated to both the clinic and the research pharmacy of Klinikum Grosshadern for study drug dispensing. 4AP was obtained from Synopharm GmbH (Barsbuettel, Germany). A total of 5 $\mathrm{mg}$ of $4 \mathrm{AP}$ and placebo was labeled and packaged in capsules that were identical in appearance and taste to those at the research pharmacy of the University Hospital Munich, Campus Grosshadern and provided directly to the study subjects. Procedures for the treatment trial are detailed in appendix e- 1 .

Side effects/toxicity monitoring. The safety analysis comprised a structured interview and clinical and laboratory examinations as well as EKGs of the subjects for possible adverse events (in alphabetical order: abdominal pain, agitation, anxiety, blurred vision, diarrhea, dizziness, epigastric discomfort or pain, gait instability, insomnia, nausea, palpitations, peripheral or oral paresthesias, postural vertigo, tremor, or seizures ${ }^{13-15}$ ). Adverse events were classified as mild, moderate, or severe.

Side effects were assessed by collecting the standardized protocol every 4 weeks after treatment onset. At this time, subjects were also asked if they had any specific side effects or any side effects at all. Treatment was discontinued for the following reasons: the patient did not want to continue, the patient exhibited poor compliance (i.e., failure to take the agent at least 6 times during the treatment period), or the patient developed severe side effects during treatment or signs or symptoms during the course of the disease that were not compatible with EA2. Subjects who failed to return for a follow-up examination after 7 months were excluded from the final analysis.

Patient self-report of ataxia episodes and quality of life: Efficacy outcome variables. The study participants documented ataxia episode frequency and duration using structured forms to submit at each clinic visit (at the end of the 1-month-long baseline period, at each 3-month-long treatment period, and at the 1-month-long washout period). At each visit, the participants also used the 28-item VDADL ${ }^{12}$ to determine their functional burden of disease on a 10-point scale $(1=$ independent to $10=$ ceasing to participate in the activity).

The primary efficacy outcome measure was the average number of attacks per month based on the patients' documented reports. Secondary outcome measures were the total duration of the attacks per month and the VDADL score ${ }^{12}$ as a measure of the burden of disease. The VDADL score was the median of all individual answers. ${ }^{12}$

Statistical analysis. The sample size was calculated using SampleStat (SPSS) and was based on a mean difference in the number of attacks between treatment and nontreatment with $4 \mathrm{AP}$ of $50 \%$ and SD of $25 \%$. This calculation yielded a sample size of 10 subjects, assuming a $t$ test for 2 dependent groups, 2-tailed, a type I error rate of $\alpha=0.01$, and power of $85 \%$. Because the frequency data are skewed, the median and the interquartile range (IQR) were used as robust measures to describe location and variability. The IQR included the central $50 \%$ of 


\begin{tabular}{|c|c|c|c|c|c|c|c|c|}
\hline \multirow{2}{*}{$\begin{array}{l}\text { Table } \\
\text { Subject } \\
\text { no. }\end{array}$} & \multicolumn{8}{|c|}{ Baseline characteristics of the subjects included in the study } \\
\hline & $\begin{array}{l}\text { Age, } \\
\text { y/sex }\end{array}$ & $\begin{array}{l}\text { Sequence of } \\
\text { treatment }\end{array}$ & $\begin{array}{l}\text { Mutation in } \\
\text { the CACNA1A gene/ } \\
\text { family history }\end{array}$ & $\begin{array}{l}\text { Ocular motor } \\
\text { findings }^{\mathrm{a}}\end{array}$ & $\begin{array}{l}\text { Other neurologic } \\
\text { deficits }\end{array}$ & $\begin{array}{l}\text { Attacks/ } \\
\mathrm{mo}^{\mathrm{b}}\end{array}$ & $\begin{array}{l}\text { Total } \\
\text { duration of } \\
\text { attacks } / \mathrm{mo}, \mathrm{h}^{\mathrm{b}}\end{array}$ & $\begin{array}{l}\text { VDADL } \\
\text { score }^{\text {b }}\end{array}$ \\
\hline 1 & $57 / M$ & Placebo/4AP & p.D1772G & $a, b$ & $\begin{array}{l}\text { Ataxic stance and } \\
\text { broad-based gait }\end{array}$ & 6 & 12 & 8 \\
\hline 2 & $41 / M$ & 4AP/placebo & p.R455X & $a, c, d$ & $\begin{array}{l}\text { Ataxic stance and } \\
\text { broad-based gait }\end{array}$ & 30 & 15 & 8 \\
\hline 3 & $13 / \mathrm{M}$ & 4AP/placebo & p.A454T/brother of no. 8 & $a, c, d$ & Mild gait ataxia & 1 & 4 & 6 \\
\hline 4 & $43 / \mathrm{M}$ & Placebo/4AP & $\begin{array}{l}\text { No mutation/positive family } \\
\text { history of ataxia of } \\
\text { mother and cousin }\end{array}$ & $a, c, d, e$ & Myotonic dystrophy & 10 & 10 & 4 \\
\hline 5 & $54 / \mathrm{M}$ & 4AP/placebo & No mutation/father of no. 6 & $a, c, d$ & Mild gait ataxia & 6 & 19 & 1 \\
\hline 6 & $17 / F$ & Placebo/4AP & No mutation/daughter of no. 5 & $a, c, d, e$ & None & 6 & 12 & 5 \\
\hline 7 & $44 / \mathrm{M}$ & Placebo/4AP & p.C256R & a & $\begin{array}{l}\text { Ataxic stance and } \\
\text { broad-based gait }\end{array}$ & 15 & 25 & 9.5 \\
\hline 8 & $30 / M$ & 4AP/placebo & p.A454T/brother of no. 3 & $a, c, d, f$ & Mild gait ataxia & 10 & 20 & 1 \\
\hline 9 & $63 / F$ & 4AP/placebo & $\begin{array}{l}\text { p.C1417fs (c. } 4252 \text { - } \\
4256 \text { delTGTCGgt); mother } \\
\text { of no. } 10\end{array}$ & $a, c, d, e$ & Broad-based gait & 27 & 35 & 10 \\
\hline 10 & $42 / F$ & 4AP/placebo & $\begin{array}{l}\text { p.C1417fs (c. } 4252- \\
4256 \text { delTGTCGgt); daughter } \\
\text { of no. } 9\end{array}$ & $a, c, e$ & Mild ataxic stance & 15 & 18 & 8 \\
\hline
\end{tabular}

Abbreviations: 4AP = 4-aminopyridine; VDADL = Vestibular Disorders Activities of Daily Living Scale.

a Ocular motor findings: $a$ = saccadic pursuit; $b$ = slow and hypometric saccades; $c$ = horizontal gaze-evoked nystagmus; $d=$ disturbed visual suppression of the vestibulo-ocular reflex; $e=$ downbeat nystagmus; $f=$ upbeat nystagmus.

${ }^{b}$ Data at baseline.

the data under study. To assess the difference in attack frequency between the 2 treatment groups, a subject-specific approach was used that was based on a Poisson mixed-effects model, with treatment and period effects being fitted as fixed. The use of a mixed model allows the retrieval of cross-subject information and meaningful estimates of the magnitude of the treatment effect. A patient-specific intercept was included as a random effect.

For secondary outcomes (attack duration and VDADL score), nonparametric procedures by the Wilcoxon test were used to compare measurements with and without 4AP. Statistical calculations were performed using the $\mathrm{R}$ software package (version 2.7.0; www.r-project.org). All reported statistical tests were 2 -sided, and the significance level was set to $5 \%$.

RESULTS Ten subjects who met the criteria for inclusion in the study were willing to participate. The diagnosis was proven to have a genetic cause in 7 of these (table).

Two novel mutations, R455X and D1772G, were absent in 96 control DNA samples. They led to a premature stop or altered a highly conserved amino acid residue, indicating pathogenicity. All 10 subjects $(7 \mathrm{men})$ finished the study after 7 months. The mean age was $40.4 \pm 16.3$ years (SD; range 13-63 years). The flow diagram for the study is shown in figure 1 .

At baseline, the median number of attacks per month was 10.00 (IQR 6.00-15.00). The median total attack duration per month was 16.50 hours (IQR 12.00-19.80). The median VDADL score was
7.00 (IQR 4.25-8.00). Baseline characteristics are summarized in the table.

Subjects receiving placebo had a median of 6.50 (IQR 2.33-13.75) attacks per month. Those receiving 4AP had a median of 1.65 (IQR 1.00-4.78). Statistical analysis with a Poisson random intercept model allowed for quantification of the treatment effect and assessment of the presence of period effects. During treatment, the mean number of attacks per month declined significantly. Administration of 4AP significantly reduced the population mean of attack frequency (reduction from $100 \%$ to $34.13 \%, 95 \%$ confidence interval $14.81 \%-78.65 \%, p=0.03$; figure 2).

For primary outcome measurement, there is no convincing evidence for a period effect $(p=0.09$; figure e-1). The median cumulative duration of attacks per month decreased from 13.65 (IQR 7.7516.00) hours during placebo to 4.45 (IQR 2.337.50) hours during ingestion of 4AP. The difference between the duration of attacks with and without $4 \mathrm{AP}$ was marginally significant $(p=0.083$, Wilcoxon test; figure e-2).

The administration of 4AP reduced the VDADL score from 6.00 with placebo (IQR 4.25-8.00) to 1.50 (IQR 1.00-4.25). The Wilcoxon signed-rank test revealed a significant decline in the VDADL score ( $p=0.022$; figure 3 ), indicating a lower burden of disease. 


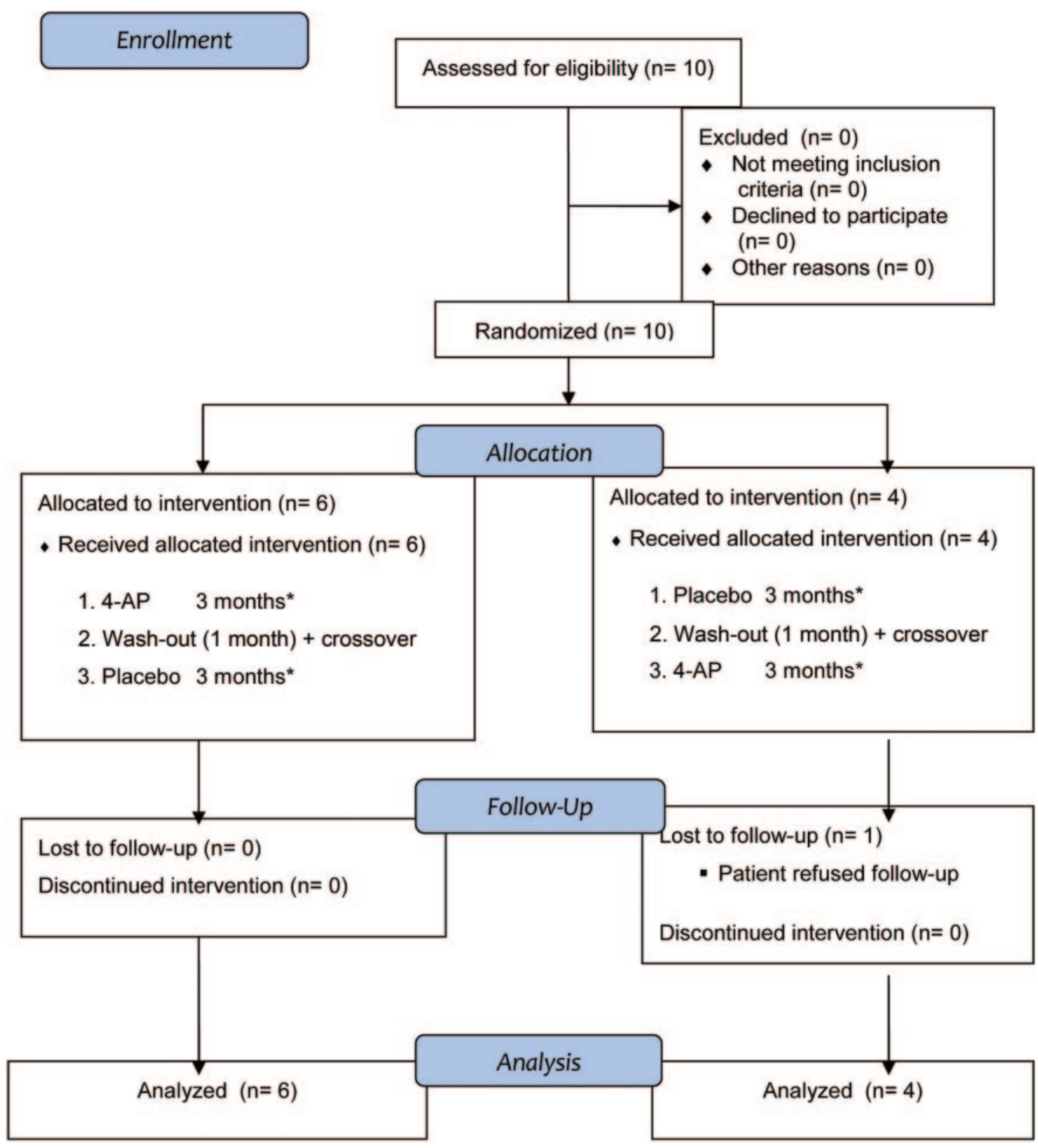

*Physical and neuro-ophthalmologic examinations, patient-reported event diary, and quality of life at the beginning and end of this period. 4AP = 4-aminopyridine.

Only minor adverse events occurred. Patients receiving 4AP reported nausea $(\mathrm{n}=2)$, epigastric discomfort $(\mathrm{n}=2)$, and palpitations $(\mathrm{n}=1)$. One patient receiving placebo treatment reported nausea. Neither $4 \mathrm{AP}$ nor placebo had to be interrupted or stopped because of side effects. The follow-up medical reports 2 years after the fourth visit and completion of the treatment trial revealed that 7 of 10 subjects continued to take 4AP; 2 subjects did not continue because of insufficient effect (subjects 1 and 6; table), and one subject did not continue because $4 \mathrm{AP}$ was rejected during treatment at a health resort (subject 4; table). Of those still taking 4AP, 2 subjects are completely free of attacks, whereas the remaining 5 subjects report reduced frequency, duration, and severity of their spells. The dose of $4 \mathrm{AP}$ varied between 10 and $15 \mathrm{mg} /$ day. None of these subjects reported side effects.

DISCUSSION A randomized controlled trial had previously established the efficacy of aminopyridines for downbeat nystagmus ${ }^{8}$ and a pilot study for EA2 in humans. ${ }^{9}$ 4AP prevented attacks of ataxia in 2 of 3 patients and markedly reduced it in the third. Cessation of the treatment led to a recurrence within 1-2 days, and subsequent therapy alleviated the symptoms. ${ }^{9}$ These findings in humans were later con- 


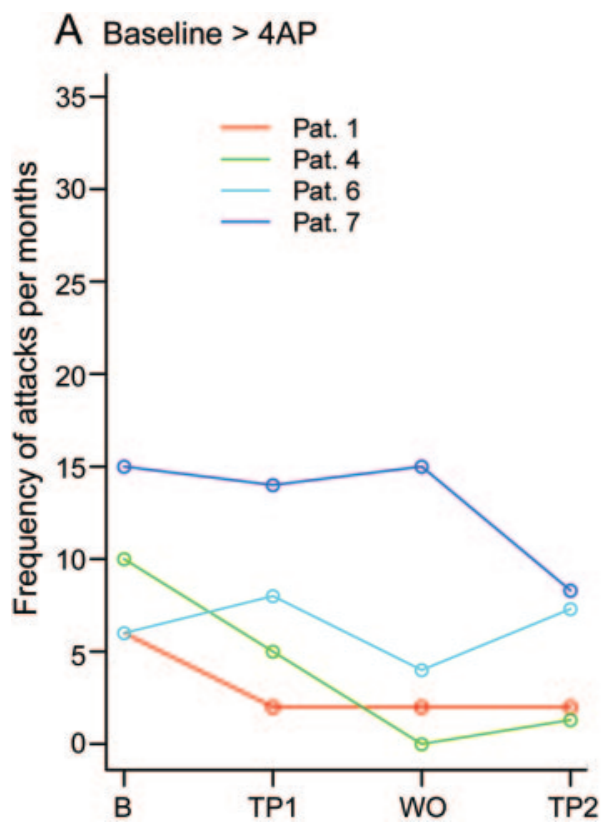

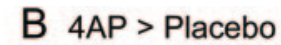

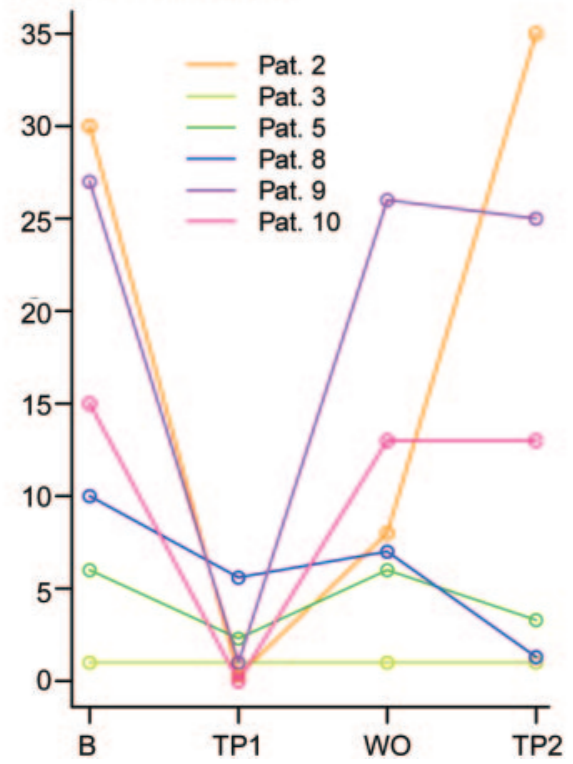

C Both sequence groups

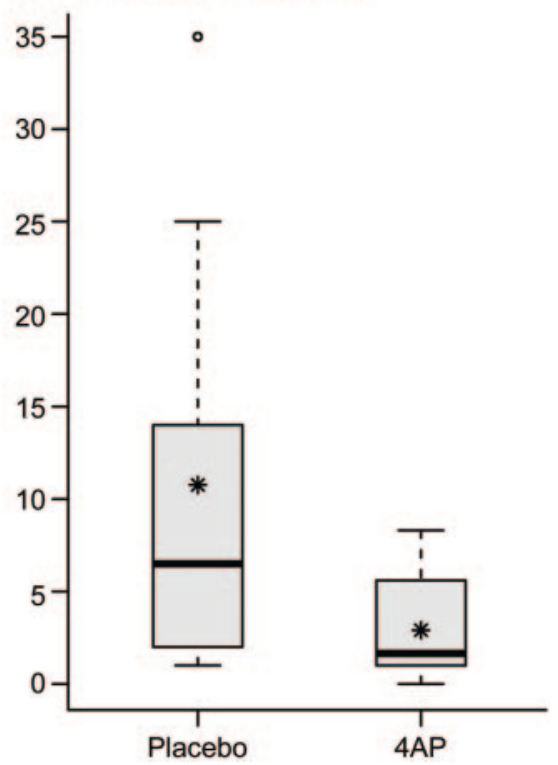

Number of attacks of ataxia per month (primary efficacy outcome measure) in the 2 treatment sequences (placebo/4-aminopyridine [4AP]; 4AP/placebo). The number was determined by the patient diary. (A, B) Trajectory plots for the 2 sequence groups (1-month baseline period [B], first 3-month treatment period [TP1], 1-month washout phase [WO], and second 3-month treatment period [TP2]). (C) Boxplots for outcome measured during the placebo and 4AP phases (box-and-whisker plot with $25 \%$ and $75 \%$ percentiles indicating the border of the box, the median [bold line], mean [asterisk], whiskers [extend to the most extreme data point, which is no more than 1.5 times the interquartile range from the box], and outliers). 4AP significantly reduced the number of attacks of ataxia per month $(p=0.03)$. Pat. $=$ patient.

firmed in the tottering mouse model of EA2. ${ }^{11}$ The present study confirmed and extended the pilot trial to demonstrate that $4 \mathrm{AP}$ significantly reduced the attack frequency and improved the quality of life in patients with EA2 and other familial EA with nystagmus not yet genetically defined.

What is the mechanism of action of 4AP in EA2 and related disorders? Ataxia in EA2 is thought to be primarily due to Purkinje cell dysfunction either in neurotransmission ${ }^{16-18}$ or the precision of pacemaking. ${ }^{19,20}$ By inhibiting the potassium currents, aminopyridines increase the duration of the action potential, thereby improving axonal conduction of action potentials and in particular the release of neurotransmitters. ${ }^{21}$ Thus, $4 \mathrm{AP}$ and 3,4-diaminopyridine have been used for the symptomatic treatment of Lambert-Eaton myasthenic syndrome, ${ }^{14,15}$ chronic spinal cord injury, ${ }^{22}$ and multiple sclerosis (MS). ${ }^{13}$ The sustained-release form of $4 \mathrm{AP}$ (Fampridine) was recently tested and approved for use in MS. ${ }^{23-25} 4 \mathrm{AP}$ was shown to reduce triggered attacks in the ataxic calcium channel mouse model tottering. ${ }^{11}$ In a recent study, 4AP did not influence the rate of activity of Purkinje cells nor did it alter synaptic transmission; however, it restored the precision of pacemaking by blocking $\mathrm{K}^{+}$channels and prolonging the action potential and increasing its amplitude of afterpolarization. ${ }^{26,27}$
4AP was well-tolerated in our study. Side effects were only minor: nausea and epigastric discomfort, each in 2 subjects, and palpitations in one patient. The appearance of only minor side effects in our study can be attributed to the low dosage $(5 \mathrm{mg} 3$ times daily). We observed no cardiac complications, as did recent studies on Fampridine. ${ }^{23-25}$

The literature reports side effects of aminopyridines such as abdominal pain, agitation, anxiety, blurred vision, diarrhea, dizziness, gait instability, insomnia, palpitations, peripheral or oral paresthesias, postural vertigo, tremor, and seizures in patients treated for Lambert-Eaton myasthenic syndrome, MS, and spinal cord injury. ${ }^{13-15}$ However, in those studies higher doses of up to $40 \mathrm{mg}$ twice daily were often used.

Our study has several limitations. First, although all study participants presented with EA with eye movement abnormalities, they did not all share the same genetic mechanisms. Indeed, although 7 of the 10 subjects were genetically diagnosed with EA2, the remaining 3 subjects did not have a mutation in $C A C N A 1 A$. However, all of these subjects had a family history of EA, suggesting a genetic predisposition in other yet to be identified EA genes. Second, only a few subjects were involved in the study because of the rarity of the disorder. Nevertheless, the beneficial effects of $4 \mathrm{AP}$ are significant and welcomed by the pa- 


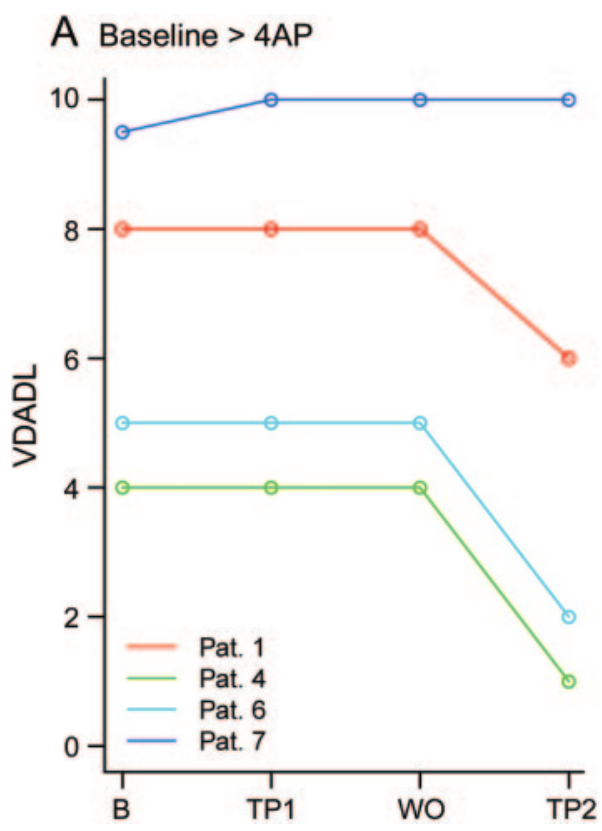

\section{B 4 AP > Placebo}

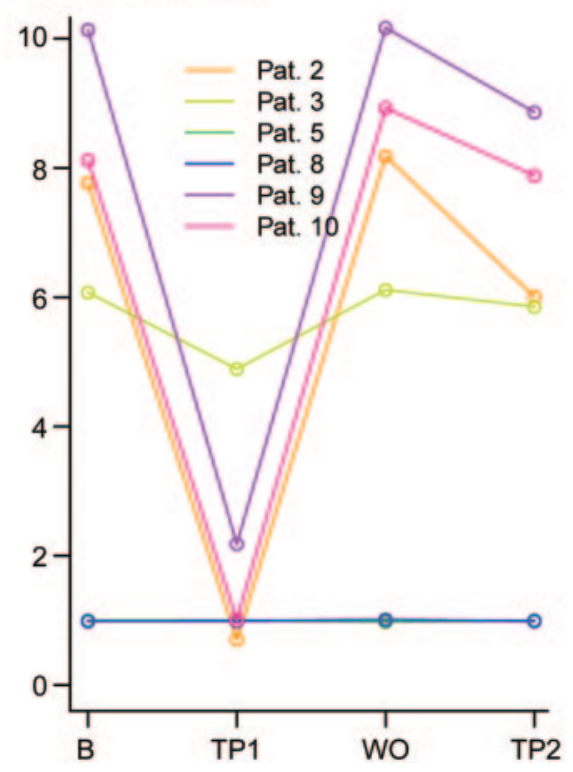

C Both sequence groups

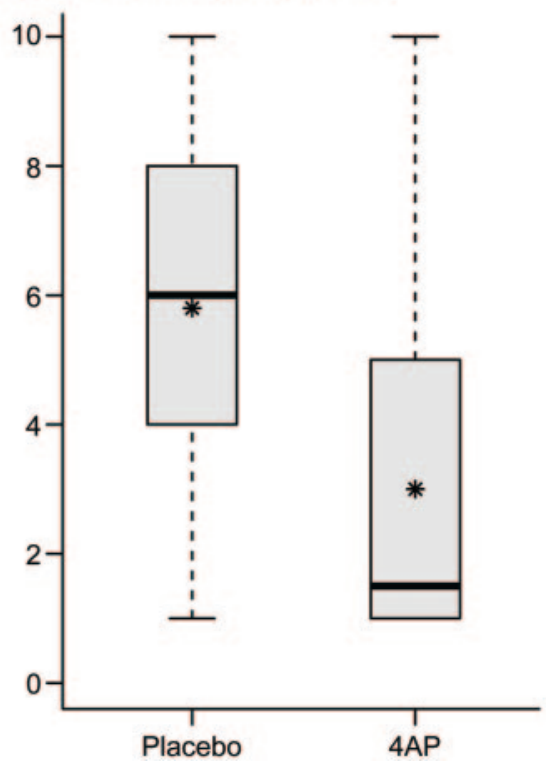

Vestibular Disorders Activities of Daily Living Scale (VDADL) score as a measure of the burden of disease (secondary outcome). (A, B) Trajectory plots for the 2 sequence groups (1-month baseline period [B], first 3-month treatment period [TP1], 1-month washout phase [WO], and second 3-month treatment period [TP2]). (C) Boxplots for outcome measured during the placebo and the 4-aminopyridine (4AP) phases (box-and-whisker plot with $25 \%$ and $75 \%$ percentiles indicating the border of the box, the median [bold line], mean [asterisk]) and whiskers [extend to the most extreme data point, which is no more than 1.5 times the interquartile range from the box]). There are no outliers. 4AP significantly reduced the VDADL score $(p=0.022)$. Pat. $=$ patient.

tients. Third, the long-term efficacy and side effects of $4 \mathrm{AP}$ were not evaluated. A study on the long-term treatment of Lambert-Eaton myasthenic syndrome with aminopyridines reported that the positive effects persisted and that no additional side effects developed. ${ }^{28}$ We anticipate that a dose-finding study and longer-term trial of 4AP in EA2 and related disorders will be necessary to assess its safety and effects on disease progression. Animal and cell studies have shown neuroprotection. ${ }^{29-31}$

Our findings demonstrate that 4AP has a prophylactic effect on ataxia attacks in EA2 and related disorders, improves the quality of life, and is welltolerated. 4AP provides an effective alternative therapeutic approach in the treatment of EA2 and related disorders for those who cannot tolerate or do not respond to acetazolamide.

\section{AUTHOR CONTRIBUTIONS}

M.S., R.K., T.K., and K.J. contributed to the study concept and design. M.S. and T.F. acquired data and recruited patients. J.C., T.K., H.N., K.J.-R., and K.J. acquired data. R.K. analyzed data. M.W., J.C., T.K., T.F. H.N., M.D. F.L.-H., K.J.-R., and K.J. analyzed and interpreted the data. R.K., J.C., C.A., U.M., and K.J. provided statistical analysis. M.S., R.S., and T.B. provided study supervision and coordination. C.A. prepared the figures. M.S., R.K., J.C., C.A., U.M., T.K., T.F., H.N., R.S., M.D. F.L.-H., K.J.-R., T.B., J.C.J., and K.J. drafted/revised the manuscript for content, including medical writing for content. M.S., R.K., and T.B. obtained funding.

\section{ACKNOWLEDGMENT}

The authors thank Judy Benson for copyediting the manuscript, Miriam Glaser and Cornelia Karch for orthoptic examination of the subjects, and Wolfgang Briegel, MD (Passau), Karin Bürk, MD (Tübingen), Bahram Mohammadi, MD (Hannover), and Elke Weimann, MD (Ludwigsburg) for patient referral.

\section{DISCLOSURE}

Prof. Strupp has received speaker honoraria from Solvay Pharmaceuticals, Inc. (now Abbott), GlaxoSmithKline, Merck Serono, Hennig Arzneimittel GmbH \& Co. KG, Pierre Fabre Laboratories, and Eisai Inc.; serves as Reviewer and Assistant Editor of the Journal of Neurology and Editor-inChief of Frontiers in Neuro-otology; receives publishing royalties for Vertigo and Dizziness: Common Complaints (Springer, 2010); and receives research support from Bundesministerium für Bildung und Forschung (BMBF) and the Deutsche Forschungsgemeinschaft (DFG). Dr. Kalla receives research support from BMBF. J.C. and C.A. report no disclosures. Prof. Mansmann serves on the editorial boards of Statistical Analysis in Genetics and Molecular Biology and PLOS Medicine; serves as a consultant for Baxter International Inc.; and receives research support from the Deutsche Forschungsgemeinschaft (DFG), the German Ministry of Technology and Research (BMFT), and the Bavarian Ministry of Health. Prof. Klopstock has received speaker honoraria from Dr. Willmar Schwabe $\mathrm{GmbH} \& \mathrm{Co}$. KG and Eisai Inc.; and receives research support from Santhera Pharmaceuticals, DFG, BMBF, and the NIH. Dr. Freilinger receives research support from Ludwig-Maximilians-Universität München, Förderung für Forschung und Lehre (FöFoLe). Dr. Neugebauer and Dr. Spiegel report no disclosures. Prof. Dichgans receives research support from BMBF, Wellcome Trust, and the Foundation for Vascular Dementia Research. Prof. Lehmann Horn reports no disclosures. Dr. Jurkat-Rott has received research support from TaroPharma, Else Kroener Fresenius Foundation, and Eva Luise Koehler Foundation. Prof. Brandt serves as the Co-Editor-in-Chief of the Journal of Neurology, Editor of Nervenarzt, and on the editorial boards of Journal of Neurological Science, Clinical Neurology and Neurosurgery, and Frontiers of Neuro- 
Otology. Dr. Jen serves as Section Editor for Developmental, Cellular and Molecular Neurobiology for Experimental Brain Research and Associate Editor for Frontiers in Neuro-otology; and receives research support from the NIH (NEI/NINDS). Dr. Jahn has received speaker honoraria from Abbott and GlaxoSmithKline and receives research support from DFG and $\mathrm{BMBF}$

Received November 3, 2010. Accepted in final form April 5, 2011.

\section{REFERENCES}

1. Ophoff RA, Terwindt GM, Vergouwe MN, et al. Familial hemiplegic migraine and episodic ataxia type- 2 are caused by mutations in the $\mathrm{Ca}^{2+}$ channel gene CACNL1A4. Cell 1996;87:543-552.

2. Griggs RC, Moxley RT 3rd, Lafrance RA, McQuillen J. Hereditary paroxysmal ataxia: response to acetazolamide. Neurology 1978;28:1259-1264.

3. Harno H, Hirvonen T, Kaunisto MA, et al. Acetazolamide improves neurotological abnormalities in a family with episodic ataxia type 2 (EA-2). J Neurol 2004;251:232-234.

4. Griggs RC, Nutt JG. Episodic ataxias as channelopathies. Ann Neurol 1995;37:285-287.

5. Jen JC, Graves TD, Hess EJ, Hanna MG, Griggs RC, Baloh RW. Primary episodic ataxias: diagnosis, pathogenesis and treatment. Brain 2007;130:2484-2493.

6. Strupp M, Zwergal A, Brandt T. Episodic ataxia type 2 . Neurotherapeutics 2007;4:267-273.

7. Jen J, Kim GW, Baloh RW. Clinical spectrum of episodic ataxia type 2. Neurology 2004;62:17-22.

8. Strupp M, Schuler O, Krafczyk S, et al. Treatment of downbeat nystagmus with 3,4-diaminopyridine: a placebo-controlled study. Neurology 2003;61:165-170.

9. Strupp M, Kalla R, Dichgans M, Freilinger T, Glasauer S, Brandt T. Treatment of episodic ataxia type 2 with the potassium channel blocker 4-aminopyridine. Neurology 2004;62:1623-1625.

10. Etzion Y, Grossman Y. Highly 4-aminopyridine sensitive delayed rectifier current modulates the excitability of guinea pig cerebellar Purkinje cells. Exp Brain Res 2001; 139:419-425.

11. Weisz CJ, Raike RS, Soria-Jasso LE, Hess EJ. Potassium channel blockers inhibit the triggers of attacks in the calcium channel mouse mutant tottering. J Neurosci 2005; 25:4141-4145.

12. Cohen HS, Kimball KT. Development of the Vestibular Disorders Activities of Daily Living Scale. Arch Otolaryngol Head Neck Surg 2000;126:881-887.

13. Bever CT Jr, Anderson PA, Leslie J, et al. Treatment with oral 3,4 diaminopyridine improves leg strength in multiple sclerosis patients: results of a randomized, double-blind, placebo-controlled, crossover trial. Neurology 1996;47: 1457-1462.

14. McEvoy KM, Windebank AJ, Daube JR, Low PA. 3,4Diaminopyridine in the treatment of Lambert-Eaton myasthenic syndrome. N Engl J Med 1989;321:1567-1571.

15. Sanders DB, Massey JM, Sanders LL, Edwards LJ. A randomized trial of 3,4-diaminopyridine in Lambert-Eaton myasthenic syndrome. Neurology 2000;54:603-607.

16. Guida S, Trettel F, Pagnutti S, et al. Complete loss of P/Q calcium channel activity caused by a CACNA1A missense mutation carried by patients with episodic ataxia type 2 . Am J Hum Genet 2001;68:759-764.

17. Wan J, Khanna R, Sandusky M, Papazian DM, Jen JC, Baloh RW. CACNA1A mutations causing episodic and progressive ataxia alter channel trafficking and kinetics. Neurology 2005;64:2090-2097.

18. Wappl E, Koschak A, Poteser M, et al. Functional consequences of $\mathrm{P} / \mathrm{Q}$-type $\mathrm{Ca}^{2+}$ channel Cav2.1 missense mutations associated with episodic ataxia type 2 and progressive ataxia. J Biol Chem 2002;277:6960-6966.

19. Hoebeek FE, Stahl JS, van Alphen AM, et al. Increased noise level of Purkinje cell activities minimizes impact of their modulation during sensorimotor control. Neuron 2005;45:953-965.

20. Walter JT, Alvina K, Womack MD, Chevez C, Khodakhah K. Decreases in the precision of Purkinje cell pacemaking cause cerebellar dysfunction and ataxia. Nat Neurosci 2006;9:389-397.

21. Smith KJ, Felts PA, John GR. Effects of 4-aminopyridine on demyelinated axons, synapses and muscle tension. Brain 2000;123:171-184.

22. Potter PJ, Hayes KC, Segal JL, et al. Randomized doubleblind crossover trial of fampridine-SR (sustained release 4-aminopyridine) in patients with incomplete spinal cord injury. J Neurotrauma 1998;15:837-849.

23. Goodman AD, Brown TR, Cohen JA, et al. Dose comparison trial of sustained-release Fampridine in multiple sclerosis. Neurology 2008;71:1134-1141.

24. Goodman AD, Cohen JA, Cross A, et al. Fampridine-SR in multiple sclerosis: a randomized, double-blind, placebocontrolled, dose-ranging study. Mult Scler 2007;13:357368 .

25. Hayes KC, Katz MA, Devane JG, et al. Pharmacokinetics of an immediate-release oral formulation of Fampridine (4-aminopyridine) in normal subjects and patients with spinal cord injury. J Clin Pharmacol 2003;43:379-385.

26. Alvina K, Khodakhah $\mathrm{K}$. The therapeutic mode of action of 4-aminopyridine in cerebellar ataxia. J Neurosci 2010; 30:7258-7268.

27. Alvina K, Khodakhah K. KCa channels as therapeutic targets in episodic ataxia type-2. J Neurosci 2010;30:72497257.

28. Jost WH, Mielke U, Forrett-Kaminsky MC, Schimrigk K. Long-term treatment of Lambert-Eaton syndrome by 3,4 diaminopyridine. Rev Neurol 1992;148:776-779.

29. Franciosi S, Ryu JK, Choi HB, Radov L, Kim SU, McLarnon JG. Broad-spectrum effects of 4-aminopyridine to modulate amyloid $\beta_{1-42}$-induced cell signaling and functional responses in human microglia. J Neurosci 2006;26: 11652-11664.

30. Ogita K, Okuda H, Watanabe M, Nagashima R, Sugiyama C, Yoneda Y. In vivo treatment with the $\mathrm{K}^{+}$ channel blocker 4-aminopyridine protects against kainateinduced neuronal cell death through activation of NMDA receptors in murine hippocampus. Neuropharmacology 2005;48:810-821.

31. Smith AJ, Tauskela JS, Stone TW, Smith RA. Preconditioning with 4-aminopyridine protects cerebellar granule neurons against excitotoxicity. Brain Res 2009;1294:165175 